\title{
The Influence Mechanism of Users' Willingness to Donate to Content Creators in Social Media
}

\author{
Wenguo Shen \\ Sun Yet-sen University \\ Xiao Long
Sun Yet-sen University
}

\begin{abstract}
As an incentive mechanism, donation to content creators in social media has become popular in China. This mechanism is greatly conducive to encourage social media content creators to release high-quality content. However, there has been little academic research about this donation behavior of social media users. This study attempts to explore factors affecting users' willingness to donate to content creators. The results indicate that the intensity of users' habit of free use of Internet has a significant negative effect on user donation attitude, and users' perception of welfare of donation has a significant positive effect. User donation attitude, collective norms, and perceived behavior control have significant positive effects on users' willingness to donation.
\end{abstract}

Keywords: Social Media, Willingness to Donate to Content Creators, Theory of Planned Behavior

\section{INTRODUCTION}

To encourage UGC and opinion formation, social media platforms allows users to donate to content creators in China. Web users can express their recognition of content creators like network anchors, online fiction writers, and owned media operators by paying money or virtual gifts to via the Internet. It is a form of consumption in which users would consume first and then pay depending on their interests.

The donation function has become a new model of user interaction in Chinese social media, as well as a new business paradigm. The donation mechanism has generated profits for emerging social media platforms like Weibo and WeChat, which are very popular in China. According to the Weibo User Development Report 2015 which was produced by Sina \& Weibo Data Center, the total amount of donation at the Weibo platform stood at RMB 44.541 million in 2015. It provides a way to liquidate highquality content and encourages content creators to produce excellent content.

Nevertheless, Zhang et al. (2015) find that only a small percentage of social media users would donate to content creators in China, and donation would decline over time. Researches on the influence factors of users' willingness to donate in social media is of great importance for social media platforms and content creators, which may help them to effectively encourage and motivate users to donate. At present, there has been little academic research about donation in social media. In a limited number of empirical studies, researchers focus on the impact of the emotional attachment on users' willingness to donate in social media, while neglecting the effects of users' perception and attitude towards donation. 
This study attempts to probe into factors affecting social media users' willingness to donation from the perspective of planned behavior. The findings may help to enhance the capability of content operators to create income and provide scientific basis for the sustainable development of content entrepreneurship.

\section{THEORETICAL BASIS AND LITERATURE REVIEW}

\section{Theory of Planned Behavior}

The theory of planned behavior is proposed to explain the decision-making process of individuals, which offer a theoretical framework for understanding how the planned behavior forms. It holds that attitude, subjective norms, and perceived behavior control are main factors affect behavior intention, and actual behavior is directly determined by its intention (Ajzen 1985). Behaviour intention is a subjective probability that a person will engage in a given behavior, thus measuring his willingness of the behavior (Fishbein \& Ajzen 1975). Behavior attitude refers to one's evaluation, both favorable and unfavorable, towards a given behavior, resulting from the considerations with respect to the consequences of the behavior. The considerations encompasses purposeful judgment, emotional judgment, and ethical judgment. The more favorable the attitude towards a behavior, the stronger behavior intention (Fishbein \& Ajzen 1975; Ajzen 1985). Subjective norms reflect one' beliefs about whether significant others think he or she should engage in the behavior (Ajzen 2002). It refers to the perceived social pressure (from family members, friends, colleagues) on a given behavior. In the decision-making process, one tends to make decisions which comply with those who are important to him; meanwhile, one's decision-making process is also affected by whether he or she is willing to behave in line with social expectations. Social expectations for different behaviors may come from different social groups. Perceived behavior control refers to individuals' perception of the ease or difficulty of performing the given behavior. It depends on the availability of resources, time, and opportunities which are required, and may be affected by various factors which may facilitate or impede the behavior (Ajzen 1991; Fishbein \& Ajzen 1975).

The theory of planned behavior has been applied in a variety of context. Relationships among constructs and relative importance of the determinants, nevertheless, vary across behaviors and contexts (Ajzen, 1991).

\section{Donation on the Street}

Wan et al. (2017) suggested that donation in social media is similar to busking or street performance. Both of them represent a noncompulsory user-pay model. Since ancient times, people would donate to performers for their busking or singing, giving a voluntary amount of money (Kushner \& Brooks 2000). Lemay Iv and Bates (2013) note that giving to buskers has two attributes: charitable attribute and consumption attribute, and they attempt to analyze the impact of religious belief on giving to buskers particularly from the perspective of charity. Ho and Au (2018) explore consumption experience of street audience and develop a Street Audience Experience (SAE) scale. Their research results show that audience experience of street performance influence the amount of money given to street performers.

\section{Donation in Social Media}

As the first study of donation in social media, Wan et al. (2017) believe that just like giving to buskers, donation in social media also features both characteristics of charity and consumption.

In previous studies on charity, people who receive donation are often individuals who have suffered from natural calamities or man-made misfortunes (Gao 2011; Small \& Simonsohn 2008). In China, although social media are usually free of charge, and users do not need to pay to view contents, some users would donate to the content creators who create content, contribute knowledge or offer services. Through donation, users wish to help content creators to live a better life, express gratitude for their contributions, and encourage them to continue offering high-quality knowledge or service. But donate or not is decided by users only after viewing the contents or experiencing the service provided by content creators or owned media - hence donation is practiced as a form of exchange for the contents or service (Wan et al. 2017). Therefore, donation in social media is different from charity as it also has characteristics of consumption. 
Up to now, academic studies on donation in social media are still at the initial stage. Among a limited number of empirical studies, Wan et al. (2017) find that donation intention is determined by the emotional attachment to the content creator and functional dependence on social media. According to the theory of planned behavior, consumer behavior is also influenced by habits and attitude. In China, the idea of free sharing on Internet has been broadly acknowledged, and Chinese Internet users have been used to free access to network information. Therefore, users' perception and attitude towards donation may also affect their willingness to donate.

\section{HYPOTHESES}

Based on the theory of planner behavior, the paper establishes a research model on users' willingness to donate (as shown in Figure 1).

\section{FIGURE 1}

\section{THEORETICAL MODEL}

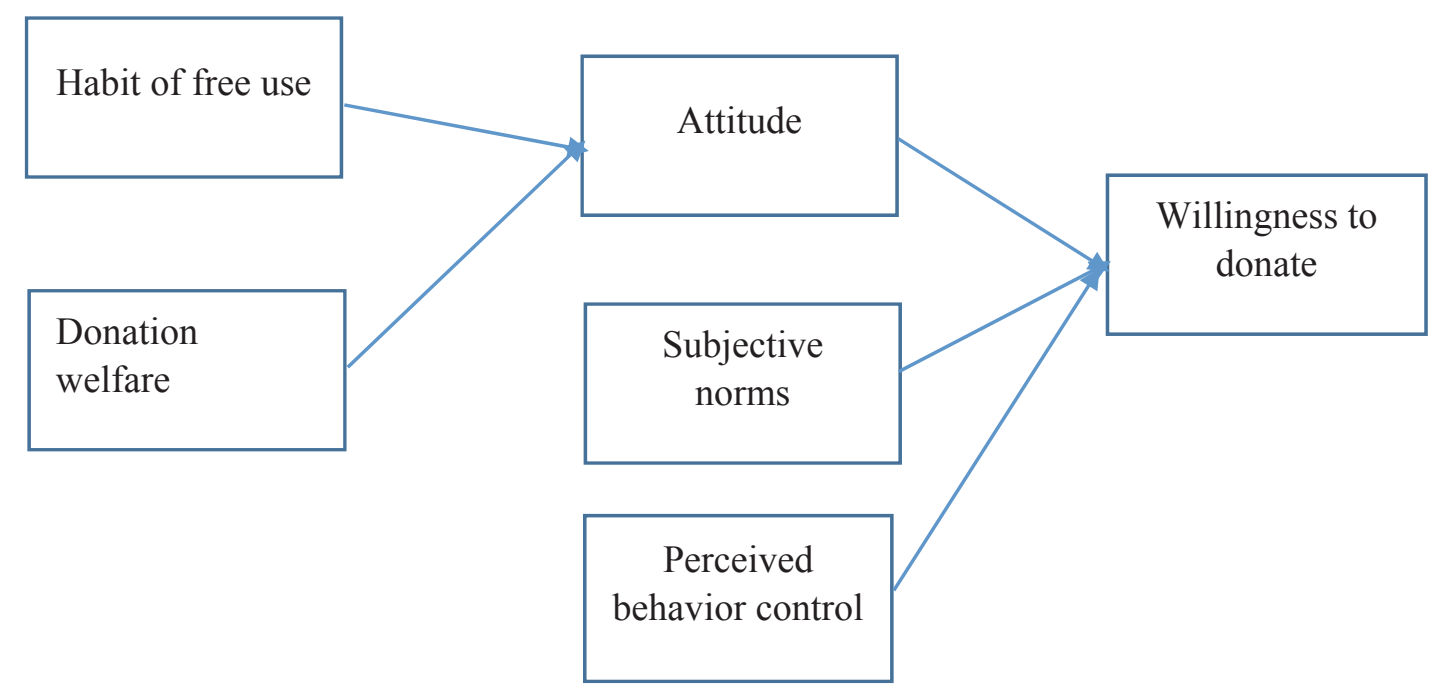

\section{Attitude}

Attitude towards donation to content creators refers to overall evaluation of donation, including judgement on the practical, ethical and emotional results (Yoon 2011). According to the theory of planned behavior, attitude plays a major role in behavior intentions (Morton and Koufteros, 2008). We suggest that on social media platforms, users who have a favorable attitude towards donation will have a relatively strong willingness to donate to content creators.

H1: Attitude toward donation to content creators has a significant positive effect on willingness to donate.

\section{Subjective Norms}

Brown (1999) believes that the "significant others" in the context of subjective norms majorly represent two groups, namely reliable group and external referent group. The theory of planned behavior suggests that if significant others or referent groups support a specific behavior, one may perceive less social pressure; If significant others or referent groups disapprove of the behavior, the individual will perceive relatively strong external pressure which may impede the performance of the behavior. We suggest the stronger the subjective norms, the stronger one's behavioral intention to donate.

H2: Subjective norms have a significant positive effect on willingness to donate. 


\section{Perceived Behavior Control}

Perceived behavior control refers to individuals' expectations, in view of past experience and behaviors, about the difficulty of performing a specific behavior as well as their capability to do it (Ajzen 2002). In the case of donation to content creators, users' Internet skills and the ease of use of platform operating systems are important factors which may affect users' perceived behavior control.

\section{H3: Perceived behavior control has a significant positive effect on willingness to donate.}

\section{Habit of Free Use}

Habit refers to the act of spontaneously performing a behavior without strong consciousness in a certain situation, and it results from past experience (d' Astous et al. 2005; Cronan \& Al-Rafee 2008). Fishbein and Ajzen (1975) find that once a person performs a certain consumer behavior, he is likely to develop a habit and continue doing so in the future. In China, most Internet users have been used to free access to network feeds. Therefore, this study employs the habit of free use as the antecedent variable of attitude. The stronger the habit of obtaining social media content with no charge, the less possibility users would donate.

\section{H4: Habit of free use of content has a significant negative effect on attitude towards donate.}

\section{Welfare of Donation}

Attitude is an evaluation of the consequences of a specific behavior. Studies of music consumption behaviors show that consumers realize that paying for music downloading may deliver some welfares, such as helping niche musicians, and boosting the development of high-quality music platforms (Weijters et al. 2014; Nuttall et al. 2011). Same as donation in busking, on social media platforms, content users demonstrate gratitude to content creators through donation, and they believe that their donation enable content creators to live a better life, and encourage creators to continue offering high-quality knowledge or services.

H5: Donation welfare brought by donation has a significant positive effect on attitude towards donation.

\section{RESEARCH DESIGN}

\section{Scale Development}

Structural Equation Modeling (SEM) was used to examine the relationship between various latent variables in the model. In order to ensure validity and reliability of measurement instruments, we used mature scales developed in existing literature and made appropriate modifications according to the research objectives and the specific situation. The scale for attitude towards donation is based on Ajzen (1992), Bagozzi (2001), and French et al. (2005); perceived behavior control is based on Ajzen and Fishibein (2000) and Fielding et al. (2008); subjective norms was adapted from Venkatesh and Davis (2000); willingness to donate is developed based on Moon and Kim (2001); welfares of bonaion from Ang et. (2001); habit of free use from Moon and Kim (2001) and d' Astous et al. (2005). The questionnaire is designed in the form of a five-point Likert scale, offering five options: 1=Strongly Disagree; $2=$ Moderately Disagree; 3=Uncertain; 4=Moderately Agree; and, 5= Strongly Agree.

\section{Questionnaire Design and Pre-survey}

In light of the popularity of WeChat in China, this paper chooses users of WeChat subscription accounts as the respondents. The questionnaire consists of two parts: 1) basic information of respondents (gender, age, occupation, education background, region, consumption level, usage of WeChat); 2) 26 indicator items for six latent variables. In order to ensure validity of survey, a pre-survey including 96 valid responses were conducted. Some fine adjustments have been made to the questionnaire based on the pre-survey results. 
The study was conducted on the platform of WJX (Www.wjx.cn), a professional online survey network in China, and received 402 complete responses. Responses which had been completed less than 100 seconds were deleted. 47 responses were identified as low-quality data through screening and excluded. 18 responses were deleted because the answers were all identical. At the end, 318 valid responses had been obtained.

\section{RESULTS}

\section{Descriptive Statistics of Sample Data}

The study involves 138 male respondents (43.4\%). Most respondents are aged between 19 and 25, accounting for $73.6 \%$ of the total, followed by those aged between 26 and $34(19.2 \%)$. A majority of the respondents are undergraduate students, accounting for $72 \%$. Among the respondents, $32.7 \%$ usually spend RMB 1,001-2,000 each month. In terms of the usage of WeChat, $47.5 \%$ of the respondents have used WeChat for 4-6 years, followed by those who have used WeChat for 2-4 years $(25.8 \%)$ and more than 6 years $(19.5 \%)$.

\section{Measurement Model}

Table 1 displays the Cronbach's $\alpha$ coefficients of latent variables in the model. The overall Cronbach's $\alpha$ coefficient stands at 0.870 , and all coefficients of individual variables are greater than the threshold value of 0.7 , showing that data had good reliability.

We examined the validity of measurement model based on Amos 22.0. The results of Confirmatory factor analysis (CFA) described the data with a satisfactory model fit: $\chi 2 / \mathrm{df}=1.899, \mathrm{p}<.001$, RMSEA $=$ $0.053, \mathrm{CFI}=0.951, \mathrm{PCFI}=0.807, \mathrm{GFI}=0.903, \mathrm{CFI}=0.951$.

TABLE 1

RELIABILITY STATISTICS

\begin{tabular}{|c|c|c|}
\hline Latent variable & Number of items & Cronbach's $\boldsymbol{\alpha}$ \\
\hline Habit of free use & 4 & 0.883 \\
\hline Welfares of tipping & 5 & 0.876 \\
\hline Attitude & 4 & 0.848 \\
\hline Subjective norms & 4 & 0.851 \\
\hline Perceived behavior control & 2 & 0.726 \\
\hline Willingness to tip & 4 & 0.839 \\
\hline Overall reliability statistics & 23 & 0.870 \\
\hline
\end{tabular}

As shown in Table 2, the Average Variance Extracted (AVE) values of all latent variables are greater than 0.5 , with the lowest being 0.573 , demonstrating a good convergent validity. The absolute values of correlation coefficients between the latent variables are apparently lower than square roots of AVE values, illustrating that the measurement model had a good discriminant validity.

To sum up, the measurement model on factors affecting users' willingness to donate represents a good model fit and satisfactory reliability and validity. Therefore, the next step is to assess the structural model in order to test the research model and examine the hypotheses.

\section{Structural Model}

The results of structural equation model fit indices are indicated good fit of the data: $\chi 2=638.897$; $\mathrm{P}=0.000 ; \quad \mathrm{df}=223 ; \quad \mathrm{RMSA}=0.069 ; \quad \chi 2 / \mathrm{df}=2.494 ; \quad \mathrm{GFI}=0.892 ; \quad \mathrm{NFI}=0.885 ; \quad \mathrm{IFI}=0.914 ; \quad \mathrm{CFI}=0.914 ;$ PNFI $=0.762$, PCFI $=0.805$, and $\mathrm{PGFI}=0.705$. 
TABLE 2

MATRIX OF CORRELATION COEFFICIENTS BETWEEN LATENT VARIABLES

\begin{tabular}{|l|l|l|l|l|l|l|}
\hline Latent variable & $\begin{array}{l}\text { Habit of } \\
\text { free use }\end{array}$ & $\begin{array}{l}\text { Welfare of } \\
\text { tipping }\end{array}$ & Attitude & $\begin{array}{l}\text { Subjective } \\
\text { norms }\end{array}$ & $\begin{array}{l}\text { Perceived } \\
\text { behavior } \\
\text { control }\end{array}$ & $\begin{array}{l}\text { Willingness } \\
\text { to tip }\end{array}$ \\
\hline $\begin{array}{l}\text { Habit of free } \\
\text { use }\end{array}$ & $\mathbf{0 . 8 1 4}$ & & & & & \\
\hline $\begin{array}{l}\text { Welfare of } \\
\text { tipping }\end{array}$ & 0.280 & $\mathbf{0 . 7 8 0}$ & 0.406 & $\mathbf{0 . 7 6 7}$ & & \\
\hline Attitude & -0.047 & 0.199 & 0.613 & $\mathbf{0 . 7 6 9}$ & & \\
\hline $\begin{array}{l}\text { Subjective } \\
\text { norms }\end{array}$ & -0.094 & 0.324 & 0.294 & 0.256 & $\mathbf{0 . 7 8 5}$ & \\
\hline $\begin{array}{l}\text { Perceived } \\
\text { behavior } \\
\text { control }\end{array}$ & 0.224 & 0.350 & 0.752 & 0.569 & 0.460 & $\mathbf{0 . 7 5 7}$ \\
\hline $\begin{array}{l}\text { Willingness to } \\
\text { tip }\end{array}$ & -0.124 & & & & & \\
\hline
\end{tabular}

As can be shown in Table 3, the results of the path coefficient showed that all hypotheses were supported. More specifically, attitude $(\beta=0.639)$, perceived behavior control $(\beta=0.276)$, and subjective norms $(\beta=0.223)$ were found to have a significant effect on users' willingness to donation, with users' attitude towards donation having the strongest magnitude on the relationship with the willingness. In addition, the negative effect of habit of free use and the that the less users are used to free access to content and the higher the perceived welfare of donation, the stronger users' attitude towards donation.

TABLE 3

TEST RESULTS OF HYPOTHESES

\begin{tabular}{|c|c|c|c|c|}
\hline $\begin{array}{c}\text { Path relationships between latent } \\
\text { variables }\end{array}$ & $\begin{array}{l}\text { Standardized } \\
\text { path } \\
\text { coefficient } \\
\text { ( } \beta \text { value })\end{array}$ & $\begin{array}{c}\text { C.R. } \\
\text { (T value) }\end{array}$ & $\begin{array}{c}\text { Significance } \\
\text { level } \\
\text { (P value) }\end{array}$ & Test result \\
\hline $\begin{array}{l}\text { H1: Users' favorable attitude has a } \\
\text { significant positive effect on their } \\
\text { willingness to tip. }\end{array}$ & 0.639 & 9.453 & $* * *$ & Valid \\
\hline $\begin{array}{l}\text { H2: Users' subjective norms have a } \\
\text { significant positive effect on their } \\
\text { willingness to tip. }\end{array}$ & 0.223 & 3.899 & $* * *$ & Valid \\
\hline $\begin{array}{l}\text { H3: Users' perceived behavior control has a } \\
\text { significant positive effect on their } \\
\text { willingness to tip. }\end{array}$ & 0.276 & 4.824 & $* * *$ & Valid \\
\hline $\begin{array}{l}\text { H4: Users' habit of free use of content has a } \\
\text { significant negative effect on their attitude } \\
\text { towards tipping. }\end{array}$ & -0.197 & -3.132 & 0.002 & Valid \\
\hline $\begin{array}{l}\text { H5: Users' perception of development } \\
\text { welfare brought by tipping has a significant } \\
\text { positive effect on their attitude towards } \\
\text { tipping. }\end{array}$ & 0.463 & 6.729 & $* * *$ & Valid \\
\hline
\end{tabular}




\section{DISCUSSION AND CONCLUSIONS}

This paper examines factors affecting users' willingness to donate to content creators in Chinese social media based on the theory of planned behavior. The results shows that user attitude toward donation, subjective norms, and perceived behavior control significantly influence users' willingness to donate. This study also reveal interesting findings on the effects of users' habit of free use and perceived donation welfare on user attitude toward donation. We found that the more users are used to free access to social media content, the more unfavorable their attitude towards donation, and the greater users' perception of donation welfare, the more favorable their attitude towards donation.

From the theoretical perspective, as donation in social media has been developing for only a few years, there are limited studies centering on this subject. This study contributes to the research of social media user behaviors, especially donation in social media through the lens of the planned behavior theory. It provides a theoretical foundation for social media platforms and content creators to effectively encourage and manage users' donation behavior, which is a good way to monetize high-quality content in social media.

This study has some implications for management practices. Social media platforms and content creators should adhere to create high-quality content, and keep updating. In order to enhance users' perceived behavior control, Social media platforms should manage to optimize the donation pattern and streamline the donation procedure. Practitioners can foster a climate of donation by enhancing interaction with users, as well as interaction between users, which may increase user stickiness. In the long run, social media platforms should help users develop the awareness of paying for high-quality content and the habit of donation, create an enabling environment to create high-quality content, which can facilitate continued offerings from content creators, increase user stickiness, and in the end, generate a virtuous cycle.

This study has several limitations. First, the research model is constructed based on the theory of planned behavior, but it neglects the impact of some factors, such as users' perceived value of content and users' impression management. Future research can incorporate more factors into the model to explain the intention to donation. Second, there is no discussion on the moderating effect of users' individual characteristics (gender, age, occupation, education background, etc.) on the relationships between variables. We suggest that these factors can be considered in the future research.

\section{ENDNOTE}

1. This work was supported by the National Natural Science Fund of China (\#71772186) and the National Natural Science Fund of Guangdong Province of China (\#2018A030313862). 


\section{REFERENCES}

Ajzen, I. (1985). From intentions to actions: A theory of planned behavior. In Action control (pp. 11-39). Springer, Berlin, Heidelberg.

Ajzen, I. (1991). The theory of planned behavior. Organizational Behavior and Human Decision Processes, 50(2), 179-211.

Ajzen, I. (2002). Perceived behavioral control, self-efficacy, locus of control, and the theory of planned behavior 1. Journal of Applied Social Psychology, 32(4), 665-683.

Ajzen, I., \& Driver, B. L. (1992). Application of the theory of planned behavior to leisure choice. Journal of Leisure Research, 24(3), 207-224.

Ajzen, I., \& Fishbein, M. (2000). Attitudes and the attitude-behavior relation: Reasoned and automatic processes. European Review of Social Psychology, 11(1), 1-33.

Bagozzi, R. P., Lee, K. H., \& Van Loo, M. F. (2001). Decisions to donate bone marrow: The role of attitudes and subjective norms across cultures. Psychology and Health, 16(1), 29-56.

Brown, T. J. (1999). Antecedents of culturally significant tourist behavior. Annals of Tourism Research, 26(3), 676-700.

Cronan, T. P., \& Al-Rafee, S. (2008). Factors that influence the intention to pirate software and media. Journal of Business Ethics, 78(4), 527-545.

d'Astous, A., Colbert, F., \& Montpetit, D. (2005). Music piracy on the web-how effective are anti-piracy arguments? Evidence from the theory of planned behaviour. Journal of Consumer Policy, 28(3), 289-310.

Fielding, K. S., Terry, D. J., Masser, B. M., \& Hogg, M. A. (2008). Integrating social identity theory and the theory of planned behaviour to explain decisions to engage in sustainable agricultural practices. British Journal of Social Psychology, 47(1), 23-48.

Fishbein, M., \& Ajzen, I. (1977). Belief, attitude, intention, and behavior: An introduction to theory and research.

French, D. P., \& Kinmonth, A. L., et al. (2005). The Importance of Affective Beliefs and Attitudes in the Theory of Planned Behavior: Predicting Intention to Increase Physical Activity 1. Journal of Applied Social Psychology, 35(9), 1824-1848.

Gao, Y. (2011). Philanthropic disaster relief giving as a response to institutional pressure: Evidence from China. Journal of Business Research, 64(12), 1377-1382.

Ho, R., \& Au, W. T. (2018). Development of Street Audience Experience (SAE) Scale. Psychology of Aesthetics, Creativity, and the Arts, 12(4), 453.

Hoon Ang, S., Sim Cheng, P., Lim, E. A., \& Kuan Tambyah, S. (2001). Spot the difference: consumer responses towards counterfeits. Journal of consumer Marketing, 18(3), 219-235.

Kushner, R. J., \& Brooks, A. C. (2000). The one-man band by the quick lunch stand: Modeling audience response to street performance. Journal of Cultural Economics, 24(1), 65-77.

Lemay, J. O. IV., \& Bates, L. W. (2013). Exploration of charity toward busking (street performance) as a function of religion. Psychological Reports, 112(2), 578-592.

Moon, S. I., Kim, K., Feeley, T. H., \& Shin, D. H. (2015). A normative approach to reducing illegal music downloading: The persuasive effects of normative message framing. Telematics and Informatics, 32(1), 169-179.

Morton, N. A., \& Koufteros, X. (2008). Intention to commit online music piracy and its antecedents: an empirical investigation. Structural Equation Modeling: A Multidisciplinary Journal, 15(3), 491512.

Nuttall, P., \& Hill, A., et al. (2011). Understanding music consumption through a tribal lens. Journal of Retailing and Consumer Services, 18(2), 152-159.

Sina \& Weibo Data Center, Weibo User Development Report. (2015). [Online]. Retrieved from https://wenku.baidu.com/view/fb073345cc22bcd127ff0cb2.html

Small, D. A., \& Simonsohn, U. (2007). Friends of victims: Personal experience and prosocial behavior. Journal of Consumer Research, 35(3), 532-542. 
Venkatesh, V., \& Davis, F. D. (2000). A theoretical extension of the technology acceptance model: Four longitudinal field studies. Management Science, 46(2), 186-204.

Wan, J., Lu, Y., Wang, B., \& Zhao, L. (2017). How attachment influences users' willingness to donate to content creators in social media: A socio-technical systems perspective. Information \& Management, 54(7), 837-850.

Weijters, B., Goedertier, F., \& Verstreken, S. (2014). Online music consumption in today's technological context: Putting the influence of ethics in perspective. Journal of Business Ethics, 124(4), 537550 .

Yoon, C. (2011). Theory of planned behavior and ethics theory in digital piracy: An integrated model. Journal of Business Ethics, 100(3), 405-417.

Zhang, C., Wu, S., Chang, S., Tian, J., \& Ding, Y. (2015). A study on the "tipping" model on selfpublishing platforms. Science Technology \& Publication, 6, 134-139. 